\title{
Impact of Low Concentration Factor Microfiltration on Milk Component Recovery and Cheddar Cheese Yield ${ }^{1}$
}

\author{
M. Neocleous, D. M. Barbano, and M. A. Rudan ${ }^{2}$ \\ Northeast Dairy Foods Research Center \\ Department of Food Science, \\ Cornell University, Ithaca, NY 14853
}

\section{ABSTRACT}

The effect of microfiltration (MF) on the composition of Cheddar cheese, fat, crude protein (CP), calcium, total solids recovery, and Cheddar cheese yield efficiency (i.e., composition adjusted yield divided by theoretical yield) was determined. Raw skim milk was microfiltered twofold using a $0.1-\mu \mathrm{m}$ ceramic membrane at $50^{\circ} \mathrm{C}$. Four vats of cheese were made in one day using milk at $1 \times, 1.26 \times, 1.51 \times$, and $1.82 \times$ concentration factor (CF). An appropriate amount of cream was added to achieve a constant casein $(\mathrm{CN})$-to-fat ratio across treatments. Cheese manufacture was repeated on four different days using a randomized complete block design. The composition of the cheese was affected by MF. Moisture content of the cheese decreased with increasing MF CF. Standardization of milk to a constant $\mathrm{CN}$-to-fat ratio did not eliminate the effect of MF on cheese moisture content. Fat recovery in cheese was not changed by MF. Separation of cream prior to MF, followed by the recombination of skim or MF retentate with cream resulted in lower fat recovery in cheese for control and all treatments and higher fat loss in whey when compared to previous yield experiments, when control Cheddar cheese was made from unseparated milk. Crude protein, calcium, and total solids recovery in cheese increased with increasing MF CF, due to partial removal of these components prior to cheese making. Calcium and calcium as a percentage of protein increased in the cheese, suggesting an increase in calcium retention in the cheese with increasing CF. While the actual and composition adjusted cheese yields increased with increasing MF CF, as expected, there was no effect of MF CF on cheese yield efficiency.

\footnotetext{
Received June 7, 2001.

Accepted March 22, 2002.

Corresponding author: D. M. Barbano; e-mail: dmb37@cornell.edu.

${ }^{1}$ Use of names, names of ingredients, and identification of specific models of equipment is for scientific clarity and does not constitute any endorsement of product by authors, Cornell University, or the Northeast Dairy Foods Research Center.

${ }^{2}$ International Food Network, Ltd., The Science and Technology Center, University of Reading, Early Gate, Whiteknights Road, Reading, RG6 6BZ, UK.
}

(Key words: Cheddar cheese, microfiltration, concentration factor, yield)

Abbreviation key: $\mathbf{C F}=$ concentration factor, $\mathbf{F D B}=$ fat on a dry basis, HCF = high concentration factor, $\mathbf{L C F}=$ low concentration factor, $\mathbf{M C F}=$ medium concentration factor, $\mathbf{M F}=$ microfiltration, $\mathbf{M N F S}=$ moisture in the nonfat substance, $\mathbf{P D B}=$ protein on a dry basis, $\mathbf{S E F}=$ solute exclusion factor, $\mathbf{S M}=$ standardized milk, $\mathbf{T N}=$ total nitrogen.

\section{INTRODUCTION}

Three approaches may be taken for UF of milk prior to cheese making: low concentration factor (LCF) UF, medium concentration factor (MCF) UF, and high concentration factor (HCF) UF. A review of the history of UF was reported by Horton (1997). Retention of serum proteins in cheese increases with increasing UF concentration factor (CF) (Green et al., 1981) and so does cheese yield efficiency. Despite the observed increase in cheese yield, MCF and HCF UF failed when used in commercial production of Mozzarella (Swientek, 1984) and Cheddar (Garrett, 1987) cheeses in the US because cheese quality did not meet customer needs. The main reason for this failure was the negative impact of the retained, undenatured serum proteins (Creamer et al., 1987) and other minor milk serum proteins (Lelievre et al., 1990) on the normal proteolytic process during the aging of these cheeses, resulting in cheese texture and flavor development defects.

A relatively new membrane filtration technology, microfiltration (MF), may address the above limitations of UF technology in the concentration of milk prior to cheese making. While UF separates small molecules, such as lactose from larger molecules such as proteins, MF allows all the small molecules and smaller, unassociated proteins through the membrane. Consequently, MF concentrates casein and calcium phosphate that is the micellar form. In contrast to UF, MF is not expected to increase the retention of serum proteins in the cheese. MF concentrates the $\mathrm{CN}$ in the MF retentate. The serum proteins pass through the membrane into the MF permeate free of casein. Therefore, it has been 
hypothesized that concentration of milk by MF prior to Cheddar cheese making would not produce the negative impacts on cheese texture and flavor development caused by UF. The MF approach would not be expected to achieve increased cheese yield efficiency (i.e., more cheese from the same amount of unconcentrated milk), because no increase in retention of serum proteins in the cheese produced from MF retentate is expected.

Very limited research has been done on $\mathrm{MF}$ of milk before cheese making. One study by St-Gelais et al. (1995) compared Cheddar cheese manufactured from unconcentrated milk (control cheese) to Cheddar cheese manufactured from MF concentrates of $1.22 \times, 1.43 \times$, and $1.66 \times \mathrm{CF}$. All milks were standardized to a constant CP-to-fat ratio. St-Gelais et al. (1995) reported that as $\mathrm{CF}$ increased, cheese $\mathrm{CP}$ content increased (25.6 to $27.5 \%$ ), while moisture, fat on a dry basis (FDB), and moisture in the nonfat substance (MNFS) of the cheese decreased from 35.8 to $34.6,52.3$ to 49.0 , and 53.7 to $50.9 \%$, respectively. Calcium concentration was significantly higher in the cheeses made from MF concentrate, compared to control cheese. There was no significant trend in cheese fat recovery with increasing $\mathrm{CF}$, but $\mathrm{CP}$ recovery was higher in the cheeses made from MF retentate. Both actual and moisture/salt-adjusted cheese yields increased with increasing CF. This suggests that using MF concentrate for cheese making can improve manufacturing efficiency by spreading fixed costs over more pounds of cheese produced per day, provided that more milk is purchased by the factory (Aplin et al., 1992).

However, in the study by St-Gelais et al. (1995), there was no mass balance for $\mathrm{CP}$, fat, calcium, or total solids recovery in cheese, whey, and salt whey. Cheese yield efficiency was not determined. By controlling the CNto-fat ratio (as suggested by St-Gelais et al., 1995) rather than the CP-to-fat ratio, we attempted to make the moisture content and other characteristics of the cheese made from unconcentrated milk and cheese made from MF retentate the same. A complete mass balance for fat, CP, calcium, and total solids was performed, and recoveries of each of these four components were calculated. In addition, theoretical yields and cheese yield efficiencies were calculated. The objective of our study was to determine the effect of MF on Cheddar cheese composition, on fat, $\mathrm{CP}$, calcium, and total solids accountability and recovery, and Cheddar cheese yield efficiency.

\section{MATERIALS AND METHODS}

\section{Milk Microfiltration}

Raw skim milk and cream were obtained from the Cornell University dairy plant on the day before cheese making. The cream was separated from skim milk at $4^{\circ} \mathrm{C}$, using a cream separator (500 Series Air-Tight Centrifuge, De Laval Separator Co., Denmark). The skim milk was mixed thoroughly, sampled, and divided into two portions. The larger portion of skim milk (400 kg) was concentrated twofold (i.e., $2 \times$ ) at $50^{\circ} \mathrm{C}$ using a pilotscale, uniform transmembrane pressure MF pilot scale system (Tetra Alcross M7 Pilot Plant Type, Tetra Pak, Denmark) equipped with a ceramic Membralox membrane (pore diameter: $0.1 \mu \mathrm{m}$; surface area: $1.7 \mathrm{~m}^{2}$ ). At a CF of $2 \times$, both the retentate and the permeate flow rates were $90 \mathrm{l} / \mathrm{h}$, with a transmembrane pressure in the range of 0.22 to 0.28 bar. The inlet pressure was about 4.2 bar and the outlet pressure was about 2.3 bar. MF retentate $(2 \times)$ was collected continuously and cooled to $4^{\circ} \mathrm{C}$ as it was collected. The smaller portion $(200 \mathrm{~kg})$ of raw skim milk was left unconcentrated for use as a control treatment.

\section{Standardized Milk Preparation and Cheddar Cheese Manufacture}

On the next day, four vats of full-fat, milled-curd Cheddar cheese were manufactured (Lau et al., 1990). Cheese making was replicated four different times starting from four different batches of skim milk and cream. The four treatments included the following target skim milk CF: $1 \times$ (control), $1.3 \times, 1.6 \times$, and $2 \times$. The $1 \times$ skim milk was not subjected to any $\mathrm{MF}$, and the $2 \times$ skim milk consisted of MF retentate only. The two remaining skim milk treatments were formulated by addition of MF permeate to the $2 \times$ retentate to achieve $1.3 \times$ and $1.6 \times \mathrm{CF}$. Raw cream (approximately $40 \%$ fat) was added to each of the four skim milks $(1 \times, 1.3 \times, 1.6 \times$, and $2 \times)$ to standardize to a constant $\mathrm{CN}$-to-fat ratio of 0.68 for all treatments. The actual $\mathrm{CF}$ of the standardized milk (SM) that were achieved, after cream addition, were: $1 \times$ (control), $1.26 \times, 1.51 \times$, and $1.82 \times$. These CF of the SM were slightly lower than the MF skim $\mathrm{CF}$, due to dilution of the skim retentate by the unconcentrated skim portion of the cream. Approximately $200,165,135$, and $110 \mathrm{~kg}$ of SM were used for the $1 \times$, $1.26 \times, 1.51 \times$, and $1.82 \times \mathrm{CF}$ cheese making, respectively. The same weight of cheese, approximately $18 \mathrm{~kg}$, was obtained from each of the four SM. The order of cheese making was randomized, with the first two vats of cheese being manufactured simultaneously, followed by the remaining two vats on the same day.

For each vat, the equivalent weight of unconcentrated, whole milk in the vat was calculated. Prior to the cheese making trial, seven cans $(360 \mathrm{ml} / \mathrm{can})$ of direct vat set starter culture were thawed, mixed in a sterile flask, dispensed into $35-\mathrm{ml}$ sterile plastic vials, and frozen by immersion into liquid nitrogen. The vials 
were then stored at $-80^{\circ} \mathrm{C}$. This procedure provided individual portions of starter culture that could be thawed uniformly during the experiment to achieve consistent starter performance and origin. A portion of starter culture was thawed in $38^{\circ} \mathrm{C}$ water for $25 \mathrm{~min}$, and then was added directly to the vat. For all four CF, $0.24 \mathrm{ml}$ of the culture that included Lactococcus lactis ssp. Lactis and Lactococcus lactis ssp. cremoris (911 DVS, Chris Hansen, Inc., Milwaukee, WI), and 0.0033 $\mathrm{ml}$ of annato food color (AFC WOS 550, Rhone Poulenc, Dairy Ingredients, Madison, WI) were added per kg of the original weight of unconcentrated milk. Thus, the amount of culture and color used per weight of cheese produced was constant across the four CF. No $\mathrm{CaCl}_{2}$ was added during cheese making. Double strength chymosin (Chy-Max, Chris Hansen, Inc., Milwaukee, WI) was used at a rate of $0.099 \mathrm{ml} / \mathrm{kg}$ of unconcentrated SM for the $1 \times$ (control) and 80,60, and $33 \%$ of this rate for the $1.26 \times, 1.51 \times$, and $1.82 \times \mathrm{SM}$, respectively. The reductions in the amounts of chymosin were based on those reported in a previous study (St-Gelais et al., 1995), our observations of curd firmness in preliminary cheese making with MF retentates, and our estimate of the potential retention of chymosin in the water phase of the cheese.

Each cold SM was heated to $31^{\circ} \mathrm{C}$, starter culture was added, and the mixture was left to ripen for 45 min. At the end of ripening, the milk was coagulated with chymosin for $30 \mathrm{~min}$ and then cut with a wire knife. After 5 min of curd healing and 10 min of gentle agitation, the temperature was gradually increased from 31 to $33^{\circ} \mathrm{C}$ during the first $15 \mathrm{~min}$ and from 33 to $38^{\circ} \mathrm{C}$ during the second 15 min of cooking, and then agitation was continued at $38^{\circ} \mathrm{C}$ until the $\mathrm{pH}$ of the whey decreased to 6.40. At this point, the whey was drained and the curd was piled in the center of the vat, and cheddared. After 15 min, the mass of knitted curd was cut into four slabs of the same size. Curd slabs were turned every 15 min until the curd $\mathrm{pH}$ decreased to 5.30. Next, the curd was milled, mixed, and salted (total salting rate of 2.7\%) in three equal portions at 10-min intervals with the curd temperature between 33 and $38^{\circ} \mathrm{C}$ before being placed in one $20-\mathrm{kg}$ stainless steel Wilson hoop per vat. After pressing for $5 \mathrm{~h}$ at about $25^{\circ} \mathrm{C}(30 \mathrm{~min}$ at $10 \mathrm{psi}$ followed by $4.5 \mathrm{~h}$ at 60 psi), the cheese was removed from the hoop, weighed, vacuum packed, and stored for $24 \mathrm{~h}$ at $4^{\circ} \mathrm{C}$ before being transferred to a $6^{\circ} \mathrm{C}$ aging room for 6 mo.

During cheese making, titratable acidity of the SM and whey was determined using a 9-ml sample and no dilution [(Marshall, 1992); method number 15.3.B]. The $\mathrm{pH}$ of SM, whey, and cheese were measured with an electrode that was standardized at $\mathrm{pH} 6.97$ and 4.03 at $38^{\circ} \mathrm{C}$ and kept immersed in $3 \mathrm{M} \mathrm{KCl}$ at $38^{\circ} \mathrm{C}$ between readings in order to keep its temperature equal to the temperature of the buffers and samples. All samples were at 35 to $38^{\circ} \mathrm{C}$ at the time of measurement.

\section{Sampling and Sample Preparation}

Prior to MF processing, the raw skim milk $\left(4^{\circ} \mathrm{C}\right)$ was mixed and sampled. The same sampling procedure was followed for cream, MF retentate, and MF permeate. Each SM was sampled from the cheese vat at $31^{\circ} \mathrm{C}$ prior to starter culture addition. All whey from each vat was collected from the beginning of whey draining to the beginning of milling, placed in one container, warmed to approximately $38^{\circ} \mathrm{C}$, mixed to ensure that the fat was uniformly dispersed, and then sampled. The salt whey was collected in two separate portions that were combined and mixed. The first portion was collected from the beginning of milling to the end of salting, and then refrigerated. The second portion of salt whey was collected during the $5 \mathrm{~h}$ pressing of the cheese. To collect the second portion, each hoop containing the milled cheese curd was placed inside a large, 8-mm thick, round-bottom drum liner (i.e., plastic bag; Uline, Dayton, NY), and all of the salt whey expelled during pressing was collected. At the end of pressing, the plastic bag containing the salt whey was removed from around the block and placed under hot tap water to disperse any fat stuck to the inside surfaces. The two portions of salt whey were combined and weighed. Immediately before analysis, the salt whey was tempered to $38^{\circ} \mathrm{C}$, mixed, and analyzed. All analyses of liquid samples (SM, whey, salt whey) were done on fresh samples.

Cheese was sampled at $3 \mathrm{~d}$ after manufacture. A 1$\mathrm{cm}$ thick, cross-sectional slice was removed from the middle of the block of cheese, cut into chunks about 2 $\times 2 \mathrm{~cm}$, and ground at low speed for about $5 \mathrm{~s}$ in a blender (Model 31BL92, Waring, New Hartford, CT) to a particle size of approximately 2 to $3 \mathrm{~mm}$. All the ground cheese particles were mixed and packed into 59-ml clear snap-lid, sample vials with no headspace, and stored at $4^{\circ} \mathrm{C}$ until analysis. All analyses of cheese samples were done on fresh samples.

\section{Chemical Analyses}

Skim milk, cream, retentate, and permeate composition. The fat content of both the skim milk [(Marshall, 1992); method number 15.8.B] and the cream [(AOAC, 2000); 33.3.18, method number 995.18] were determined for CN-to-fat standardization. The fat content of the $2 \times \mathrm{MF}$ retentate was expected to be twice the fat content of the initial skim milk. The total nitrogen (TN) [(AOAC, 2000); 33.2.11, method number 991.20], and the noncasein nitrogen [(AOAC, 2000); 
33.2.64, method number 998.05] contents of skim milk, cream, and retentate were also measured so that the $\mathrm{CN}$ content for each liquid ingredient could be calculated. Under the MF conditions used in this study, the MF permeate contained no detectable CN (by SDSPAGE, data not shown) or fat (by Mojonnier, data not shown).

SM, whey, and salt whey composition. Total solids, fat, TN, NPN, and calcium in SM, whey, and salt whey were determined in duplicate using forced air oven drying [(AOAC, 2000; 33.2.44, method number 990.20], ether extraction [(AOAC, 2000); 33.2.26, method number 989.05], Kjeldahl [(AOAC, 2000; 33.2.11, method number 991.20], Kjeldahl [(AOAC, 2000; 33.2.12, method number 991.21], and atomic absorption spectroscopy (Metzger et al., 2000), respectively. For calcium analysis of SM, whey, and salt whey, a $0.75-\mathrm{ml}$ sample was blended with TCA solution as described by Metzger et al. (2000). Five $\mathrm{ml}$ of SM and salt whey TCA filtrate and $10 \mathrm{ml}$ of whey TCA filtrate were used for calcium analysis to keep the calcium concentrations within the working range of the standard curve. The noncasein nitrogen [(AOAC, 2000); 33.2.64, method number 998.05] and NPN [(AOAC, 2000); 33.2.12, method number 991.21] of SM were determined in duplicate. Calculations for content of true protein and $\mathrm{CN}$ content of the $\mathrm{SM}$ were $(\mathrm{TN}-\mathrm{NPN}) \times 6.38$ and $(\mathrm{TN}$ - noncasein nitrogen $) \times 6.38$, respectively. The salt content of the salt whey was determined in duplicate using the Volhard procedure [(Marshall, 1992); method number 15.5.B], using a $0.5-\mathrm{ml}$ sample.

Cheese composition and $\mathrm{pH}$. Cheese moisture content was determined gravimetrically by drying approximately $2 \mathrm{~g}$ of cheese at $100^{\circ} \mathrm{C}$ in a forced air-drying oven (Model OV-490A-2, Blue M, Blue Island, IL) for $24 \mathrm{~h}$ [(AOAC, 2000); 33.2.44, method number 990.20]. Cheese fat, salt, and calcium content were determined by the Babcock method [(Marshall, 1992); method number 15.8.2.D], the Volhard procedure [(Marshall, 1992); method number 15.5.B], and the atomic absorption spectroscopy (Metzger et al., 2000), respectively. CP was measured by the Kjeldahl method [(AOAC, 2000); 33.2.11, method number 991.20], multiplying by 6.38 . Determination of the cheese $\mathrm{pH}$ was done using a Xerolyt electrode (Model HA405; Ingold Electrode, Willmington, MA) on cheese samples tempered to $20^{\circ} \mathrm{C}$. Moisture was determined in quadruplicate, while duplicate analyses were done for all other components.

\section{Experimental Design and Statistical Analysis}

A $4 \times 4$ complete randomized block design was used. Cheese was made on $1 \mathrm{~d}$ in each of four different weeks. In each week, a new set of milk ingredients were used.
On each of the four different weeks of cheese manufacture, four SM of four different CF $(1 \times, 1.26 \times, 1.51 \times$, and $1.82 \times)$ were used in $1 \mathrm{~d}$ to make Cheddar cheese. In the ANOVA model, CF (i.e., treatment) was analyzed as a continuous variable, while cheese making week (i.e., batch of milk) was blocked. The interaction term between $\mathrm{CF}$ and cheese making week was used as the error term for treatment. The PROC GLM procedure of $\mathrm{SAS}^{\circledR}$ was used for all data analyses (SAS User's Guide, 1990).

\section{Fat, CP, Calcium, and Total Solids Recovery}

A mass balance was done for each vat of cheese (Metzger et al., 2000). The weights of all inputs (cream, skim milk, retentate, permeate, salt) and outputs (whey, salt whey, cheese) were determined to the nearest $\mathrm{g}$ (Model PE 24, Mettler Instrument Co., Hightstone, NJ) during the experiment. The balance was calibrated with reference weights at the beginning of each cheese making day.

The actual percentage fat recovery in the whey, salt whey, and cheese was calculated, as previously described (Metzger et al., 2000) as the weight of fat present in each one of these products, divided by the fat present in the original SM, and multiplied by 100 . The total, actual fat recovery was the sum of the weight of fat in the whey, salt whey, and cheese divided by the weight of fat in the original SM. If there were no significant differences in total actual fat recovery among the four treatments for the full $4 \times 4$ cheese making trial, then the actual fat recoveries were adjusted. The actual recovery for each of the whey, salt whey, and cheese was divided by the mean total actual fat recovery on each cheese making day and then multiplied by 100 , as described previously (Rudan et al., 1998 and 1999). These calculated values are called adjusted recoveries. This brought the mean value for the cheese making trial to $100 \%$, thus allowing direct comparison of the results of this trial with other trials and previous studies on Cheddar cheese yield. The same calculation procedure was performed for $\mathrm{CP}$, calcium, and total solids recovery.

For total milk solids recovery, additional calculations were done before the calculation of the actual recovery. The salt whey and cheese samples contained added $\mathrm{NaCl}$, and the contribution of the salt to the total solids content of the salt whey and cheese was subtracted.

\section{Yield and Yield Efficiency}

Actual, adjusted, and theoretical cheese yields, and cheese yield efficiency were calculated using a procedure similar to that used for Mozzarella by Metzger et 
al. (2000). Actual yield was calculated for each vat of cheese as the weight of cheese (plus curd samples taken during the cheese making process) divided by the weight of original SM in the vat (minus the weight of the milk samples removed from the vat before rennet addition), multiplied by 100 . Adjustment of the actual cheese yields to a reference (target) cheese moisture and salt content, in this case 37 and $1.5 \%$, respectively, was done to eliminate effects of variation in moisture and salt content from vat to vat and among treatments on the yield evaluation.

Theoretical cheese yields were calculated using the Van Slyke and the Barbano cheese yield formulas. The Van Slyke formula is as follows: Cheddar Cheese Yield $=[(0.93 \times$ percent fat in the milk $)+($ percent $\mathrm{CN}$ in the milk - 0.1) $] \times 1.09 /[1$ - (target cheese moisture/100) .

The Barbano cheese yield formula takes into consideration the nonfat solids content of the separated whey to estimate the amount of whey solids retained in the water phase of the cheese (Barbano, 1996). This formula is as follows: Yield $=(\mathrm{A}+\mathrm{B}+\mathrm{C}) /(1-(($ target cheese moisture + target cheese salt)/100)), where, $\mathrm{A}$ is the milk fat recovered in the cheese, $\mathrm{B}$ is the milk $\mathrm{CN}$ plus calcium phosphate recovered in the cheese, and $\mathrm{C}$ is the other milk solids recovered in the cheese (i.e., nonfat, noncasein, nonbound calcium phosphate milk solids).

$\mathrm{A}=(0.93) \times($ percent fat in the milk $)$

$\mathrm{B}=($ percent $\mathrm{CN}$ in the milk -0.1$) \times($ calcium phosphate retention factor)

$\mathrm{C}=[(((\mathrm{A}+\mathrm{B}) /(1$ - $($ actual cheese moisture percent $/$ $100))-(A+B)) \times($ separated whey solids percent / 100)] $\times$ (solute exclusion factor)

The calcium phosphate retention factor used in the formula was 1.092. A value for solute exclusion factor (SEF) was calculated based on the observed retention of nonfat, noncasein milk solids for the four control vats of cheese in this study. Cheese yield efficiency was calculated as the moisture and salt adjusted cheese yield as a percentage of the theoretical yield, using each theoretical yield formula.

\section{RESULTS AND DISCUSSION}

\section{Retentate and Permeate Composition}

$\mathrm{CP}$, true protein, and CN content (mean ( SD) of skim milk, MF permeate, and MF retentate were $3.14 \% \pm$ $0.02,2.91 \% \pm 0.01,2.39 \% \pm 0.01,0.76 \% \pm 0.01,0.53 \%$ $\pm 0.004,0.00 \% \pm 0.00,5.54 \% \pm 0.04,5.31 \% \pm 0.04$, and $4.71 \% \pm 0.04$. The mean NPN content was the same for all three materials. The skim milk $\mathrm{CF}$ achieved by the MF system (averaged for the $4 \mathrm{wk})$ was $1.975 \times( \pm 0.01)$, which is very close to the target value of $2 \times$.

\section{SM, Whey, Salt Whey, and Cheese Composition}

SM composition and microbiology. The SM compositions are shown in Table 1 . The CP, true protein, $\mathrm{CN}$, serum protein, and fat content of the SM increased $(P<0.01)$ with increasing $\mathrm{CF}$. The $\mathrm{CN}$ as a percentage of true protein increased with increasing CF because milk serum protein was being removed with the MF permeate. However, the fact that the serum protein concentration increased $(P<0.01)$ would indicate that some of the high molecular weight milk serum proteins, such as $\alpha$-macroglobulin, may not pass through the MF membrane (Jost et al., 1999). The NPN content of the $\mathrm{SM}$, as well as the CN-to-fat ratio, was the same for all $\mathrm{CF}$. The $\mathrm{CN}$ to fat ratio did not change because it was controlled at 0.68 among treatments by cream addition. Total solids, as well as calcium content of SM increased $(P<0.01)$ with increasing $\mathrm{CF}$, but no difference $(P>$ $0.05)$ in $\mathrm{pH}$ was detected.

The coliform, standard plate count, and SCC of the raw SM are shown in Table 2. While the microbial counts increased with increasing $\mathrm{CF}$ as would be expected because they do not pass through the membrane, the overall microbiological and the SCC quality of the raw SM was good.

Whey and salt whey composition. Significant increases with increasing $\mathrm{CF}$ were observed (Table 1) in $\mathrm{CP}, \mathrm{NPN}$, fat, and total solids content $(P<0.01)$ of whey. No significant difference $(P>0.05)$ in calcium content of whey with increasing $\mathrm{CF}$ was detected. Salt whey composition was much more variable than whey composition (Table 1). Only salt content significantly increased $(P<0.05)$ with increasing $\mathrm{CF}$. No difference $(P>0.05)$ was detected in CP, NPN, fat, total solids, and calcium content due to $\mathrm{CF}$.

Cheese composition. Cheese composition for the four $\mathrm{CF}$ is shown in Table 1. Even though no significant difference in fat content was detected $(P>0.05)$, a small decrease in the FDB with increasing $\mathrm{CF}$ was detected $(P<0.05)$. CP content of the cheese increased with increasing CF $(P<0.01)$, protein on a dry basis (PDB) did not change, and the moisture content and the MNFS of the cheese decreased $(P<0.01)$. No change $(P>0.05)$ in salt, salt to moisture ratio, as well as cheese $\mathrm{pH}$ with $\mathrm{CF}$ was detected. Both calcium and calcium as a percentage of protein increased significantly with increasing $\mathrm{CF}(P<0.01)$.

The composition results agree to a great extent with previous work performed by St-Gelais et al. (1995). They found that as the protein concentration (or $\mathrm{CF}$ ) in the SM increased (CF used were $1.22 \times, 1.43 \times$, and $1.66 \times)$, the cheese $\mathrm{CP}$ concentration increased, while moisture, FDB, and MNFS of the cheese decreased significantly. In the same study, it was also shown that 
Table 1. Mean ( $\mathrm{n}=4$ ) standardized milk (SM), whey, salt whey, and cheese composition.

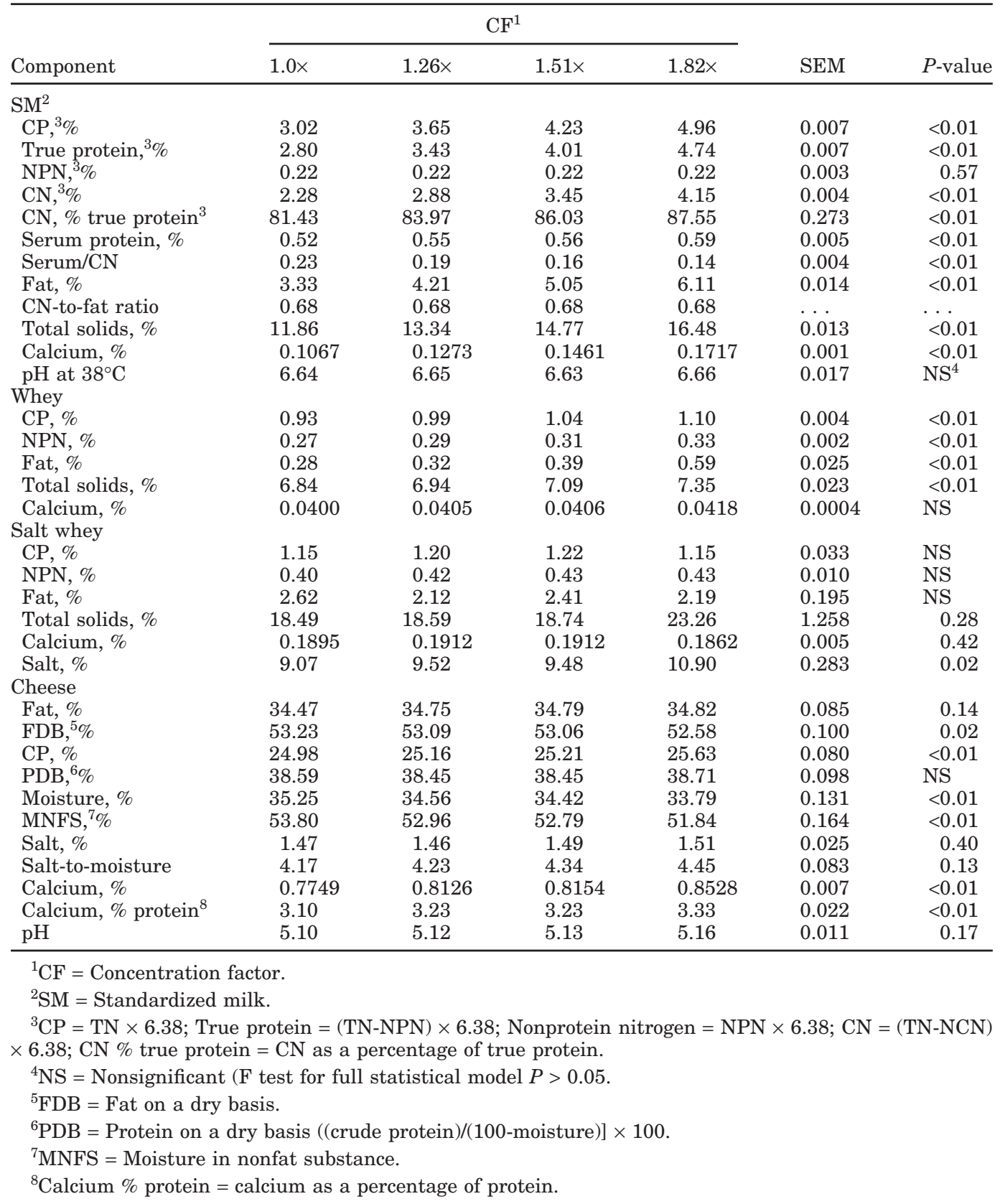

calcium concentration was significantly lower in the control cheese than in the MF cheeses. St-Gelais et al. (1995) controlled the CP to fat ratio in the SM among treatments. They recommended that to increase the moisture and the FDB of the MF cheeses, control of the $\mathrm{CN}$-to-fat ratio of the SM would be required. In our study, the CN-to-fat ratio was controlled to a constant value of 0.68 , but similar significant differences in the moisture, $\mathrm{CP}$, and MNFS between the control and MF cheeses were still detected. As expected, the FDB content of the cheese in our work (Table 1) did not decrease as much with increasing $\mathrm{CF}$ (due to our control of the $\mathrm{CN}$-to-fat ratio in the milk) as that reported by StGelais et al. (1995). Further modification of the cheese making procedure will be needed when using MF retentates, to increase cheese moisture content to a level equal to a non-MF (control) cheese.

\section{Fat, CP, Calcium, and Total Solids Recoveries}

Fat recovery. The actual (i.e., as measured) mean total fat recoveries were $99.73,99.17,99.29$, and $98.96 \%$ 
Table 2. Mean $(\mathrm{n}=4)$ and SD of coliform $(\mathrm{cfu} / \mathrm{ml})$, standard plate count (cfu/ml), and SCC per $\mathrm{ml}$ of the raw standardized milks (SM).

\begin{tabular}{llrrrr}
\hline & & \multicolumn{5}{c}{$\mathrm{CF}^{1}$} \\
\cline { 3 - 6 } & $\mathrm{SD}$ & $1.0 \times$ & $1.26 \times$ & $1.51 \times$ & $1.82 \times$ \\
\cline { 3 - 6 } Coliform & $\overline{\mathrm{X}}$ & 0.8 & 1.3 & 2.2 & 1.8 \\
& $\mathrm{SD}$ & 0.8 & 1.0 & 1.6 & 1.3 \\
Standard & $\overline{\mathrm{X}}$ & & & & \\
plate count & $\mathrm{X}$ & 6.7 & 22.3 & 21.5 & 38.9 \\
& $\mathrm{SD}$ & 4.3 & 29.4 & 26.0 & 54.4 \\
SCC & $\mathrm{X}$ & 87.0 & 59.0 & 72.0 & 81.0 \\
& $\mathrm{SD}$ & 21.9 & 15.0 & 19.8 & 22.4 \\
\hline
\end{tabular}

${ }^{1} \mathrm{CF}=$ Concentration factor.

for the $1.0 \times, 1.26 \times, 1.51 \times$, and $1.82 \times \mathrm{CF}$, respectively. No significant difference $(P>0.05)$ in actual total fat recovery among treatments was detected. Therefore, the data were adjusted to an average value of $100 \%$ recovery for the $4 \times 4$ cheese making trial (Table 3 ). No significant effect $(P>0.05)$ of MF CF on fat recovery in cheese, whey, and salt whey was detected.

The fat recovery in cheese, whey, and salt whey were $91.74,7.59$, and $1.12 \%$, respectively, for the control cheese making in the current study. The adjusted fat recovery for the control cheese was slightly less (91.7\%) than the expected (93\%) theoretical fat recovery. The adjusted fat recoveries in the present study were compared to the average adjusted fat recovery in the control cheeses of three previous cheese yield studies performed under similar conditions in our laboratory (Lau et al., 1990; Barbano et al., 1991; Barbano and Rasmussen, 1992). The average adjusted fat recovery values in the cheese, whey, and salt whey for the control cheeses in these three studies were $93.40,5.54$, and $1.06 \%$, respectively. We observed lower fat recovery in the control cheese in the current study and consequently, higher fat losses in the whey relative to the previous studies. The key difference between the current study and the previous studies in our laboratory was the separation of whole milk (into cream and skim) prior to cheese making and the recombination of skim milk and cream. This was not done in any of the previous studies (Lau et al., 1990; Barbano et al., 1991; Barbano and Rasmussen, 1992). Even though determination of the effect of separation of whole milk and recombination of skim and cream on fat recovery was not the objective of the present study, the observed differences between studies are worth noting as a caution about the potential effects of mechanical cream separation on fat recovery in cheese making. Further study on the impact of cream separation and damage to milk fat globules on fat recovery is needed.

In the current study, there was no significant effect of $\mathrm{CF}$ on fat recovery, but there was a lower fat recovery $(91.7 \%)$ in the control cheese compared to the theoretical value of $93 \%$. A study on the use of MF retentate in making Cheddar cheese by St-Gelais et al. (1995) also reported fat recoveries in cheese. Cheeses from $1 \times$ (control), $1.22 \times, 1.43 \times$, and $1.66 \times \mathrm{SM}$ were made, and it was observed that fat recoveries were $88.5,89.8,89.0$, and $87.9 \%$, respectively. The fat recovery of the control

Table 3. Adjusted mean $(n=4)$ fat, $C P$, calcium, and total solids recoveries in the cheese, whey, and salt whey.

\begin{tabular}{|c|c|c|c|c|c|c|}
\hline \multirow{2}{*}{$\begin{array}{l}\text { Component } \\
\text { recovery }\end{array}$} & \multicolumn{4}{|c|}{$\mathrm{CF}^{1}$} & \multirow[b]{2}{*}{ SEM } & \multirow[b]{2}{*}{$P$-value } \\
\hline & $1.0 \times$ & $1.26 \times$ & $1.51 \times$ & $1.82 \times$ & & \\
\hline \multicolumn{7}{|l|}{ Fat } \\
\hline Cheese & 91.74 & 92.46 & 92.43 & 91.06 & 0.397 & NS \\
\hline Whey & 7.59 & 6.57 & 6.64 & 7.94 & 0.412 & NS \\
\hline Salt whey & 1.12 & 0.86 & 0.93 & 0.67 & 0.089 & NS \\
\hline Total & 100.44 & 99.88 & 99.99 & 99.67 & 0.189 & NS \\
\hline \multicolumn{7}{|l|}{$\mathrm{CP}$} \\
\hline Cheese & 72.43 & 76.08 & 78.88 & 81.43 & 0.294 & $<0.01$ \\
\hline Whey & 27.27 & 23.39 & 20.49 & 17.94 & 0.345 & $<0.01$ \\
\hline Salt whey & 0.54 & 0.55 & 0.56 & 0.43 & 0.035 & NS \\
\hline Total & 100.24 & 100.02 & 99.94 & 99.81 & 0.110 & NS \\
\hline \multicolumn{7}{|l|}{ Calcium } \\
\hline Cheese & 63.68 & 70.62 & 74.05 & 78.41 & 0.679 & $<0.01$ \\
\hline Whey & 33.28 & 27.44 & 23.19 & 19.74 & 0.627 & $<0.01$ \\
\hline Salt whey & 2.51 & 2.53 & 2.54 & 2.01 & 0.153 & NS \\
\hline Total & 99.46 & 100.59 & 99.78 & 100.16 & 0.437 & NS \\
\hline \multicolumn{7}{|l|}{ Total solids } \\
\hline Cheese & 47.19 & 53.55 & 58.09 & 62.51 & 0.512 & $<0.01$ \\
\hline Whey & 51.58 & 45.28 & 40.45 & 36.45 & 0.578 & $<0.01$ \\
\hline Salt whey & 1.13 & 1.16 & 1.22 & 1.39 & 0.123 & NS \\
\hline Total & 99.91 & 99.99 & 99.75 & 100.35 & 0.204 & NS \\
\hline
\end{tabular}

${ }^{1} \mathrm{CF}=$ Concentration factor. 
cheese was lower than the theoretical $93 \%$, and this agrees with our results. St-Gelais et al. (1995) also used cream separation and recombination for their control cheese. Therefore, it is possible that cream separation and recombination lower the fat recovery in cheese making, if there is damage to the milk fat globules.

$\boldsymbol{C P}$ recovery. In our study, the actual (i.e., as measured) CP recoveries were 100.98, 100.76, 100.68, and $100.54 \%$ for the $1 \times, 1.26 \times, 1.51 \times$, and $1.82 \times \mathrm{CF}$, respectively. No significant difference $(P>0.05)$ among treatments was detected. Therefore, adjusted $\mathrm{CP}$ recoveries were calculated and are shown in Table 3. Adjusted $\mathrm{CP}$ recovery in the cheese increased $(P<0.01)$ with increasing $\mathrm{CF}$, decreased $(P<0.01)$ in the whey, and did not change $(P>0.05)$ in the salt whey.

The adjusted CP recoveries in cheese, whey, and salt whey $(72.43,27.27$, and $0.54 \%$, respectively) in the control cheese in the current study were compared with the adjusted CP recoveries observed in three other studies (Lau et al., 1990; Barbano et al., 1991; Barbano and Rasmussen, 1992) conducted in our laboratory. For these three previous studies, the average adjusted $\mathrm{CP}$ recovery in the cheese, whey, and salt whey were 74.62 , 24.66 , and $0.72 \%$, respectively. The adjusted CP recovery in the cheese in the current study was lower than these previous studies. This difference was due almost completely to the difference between the NPN content (expressed as NPN $\times 6.38$ ) of the milk used in the current study $(\mathrm{NPN}=0.22 \%)$ and the milk used in the other three studies (average NPN $=0.167 \%$ ). The high NPN content of the milk used in the current study was due to a change in the feeding of the cows in the Cornell dairy herd to increase milk production per cow. This change in feeding also resulted in an increase of the NPN content of milk.

A study on the use of MF retentate in making Cheddar cheese by St-Gelais et al. (1995) also reported CP recoveries in cheese. Cheeses from $1 \times, 1.22 \times, 1.43 \times$, and $1.66 \times \mathrm{SM}$ were made, and it was observed that $\mathrm{CP}$ recoveries were $75.9,79.0,80.9$, and $82.8 \%$, respectively. These results can be compared to our cheese CP recoveries (Table 3 ). The $\mathrm{CP}$ recoveries in our study (Table 3) are lower than St-Gelais et al. (1995) due to the higher NPN content of the milk in our study $(0.22 \%)$ compared to the milk used by St-Gelais et al. (1995), which was $0.15 \%$.

The observed trend of increasing $\mathrm{CP}$ recovery in cheese with increasing CF for the current study (Table 3) agrees with the study by St-Gelais et al. (1995). This trend was expected because some of the serum protein that would have been lost in the whey during cheese making had already been removed by MF prior to cheese making. There was little or no difference due to $\mathrm{MF} \mathrm{CF}$ on $\mathrm{CP}$ recovery from the original unconcen- trated milk because PDB in the cheese (Table 1) did not change significantly $(P>0.05)$ with $C F$. No effect $(P>0.05)$ of $\mathrm{CF}$ on $\mathrm{CP}$ recovery in the salt whey was detected.

Calcium recovery. Total actual (i.e., as measured) calcium recovery was $99.97,101.11,100.30$, and $100.69 \%$ for $1 \times, 1.26 \times, 1.51 \times$, and $1.82 \times \mathrm{CF}$, respectively. No significant difference in total actual calcium recovery $(P>0.05)$ was observed among treatments and, therefore, the data were adjusted, as described earlier. Calcium recovery increased $(P<0.01)$ in the cheese and decreased $(P<0.01)$ in the whey with increasing $\mathrm{CF}$. Part of the original milk calcium, instead of being lost in the whey during cheese making, had already been removed from the milk by the MF prior to cheese making. Thus, a large increase in the percentage of calcium recovery in the cheese was expected, as observed for protein. However, because there was a significant increase of calcium percentage in the cheese and calcium as a percentage of protein in the cheese (Table 1), there was a direct effect of $\mathrm{CF}$ that caused increased calcium retention in cheese under the conditions of cheese making in this study. No other data on calcium recovery in MF cheese making could be found in the literature.

Total solids recovery. Total actual (i.e., as measured) total solids recovery was 99.48, 99.57, 99.33, and $99.93 \%$ for the $1 \times, 1.26 \times, 1.51 \times$, and $1.82 \times \mathrm{CF}$, respectively. No significant difference $(P>0.05)$ in total solids among treatments was detected. Therefore, adjusted total solids recoveries were calculated and are shown in Table 3. Adjusted total solids recovery increased ( $P$ $<0.01)$ in the cheese, decreased $(P<0.01)$ in the whey, and did not change in the salt whey with increasing CF. Part of the total solids in milk, instead of being lost in the whey, had already been removed from the milk by the MF prior to cheese making. Thus, a large increase in the percentage of total solids recovery in the cheese was expected.

\section{Cheese Yield and Cheese Yield Efficiency}

Calculation of the SEF. The Barbano theoretical cheese yield formula requires the use of a SEF (Barbano, 1996) to reflect the portion of the water phase of the cheese that is available to act as a solvent for nonfat, noncasein milk solids. In the present study, a SEF for Cheddar cheese was derived from the data for the four control vats. Using the actual milk composition data, observed fat and protein recoveries, the actual cheese moisture and salt content, 1.092 for the calcium phosphate retention factor, and the actual cheese yield for each of the four control vats of cheese, one can solve the yield equation for SEF. The mean SEF calculated 


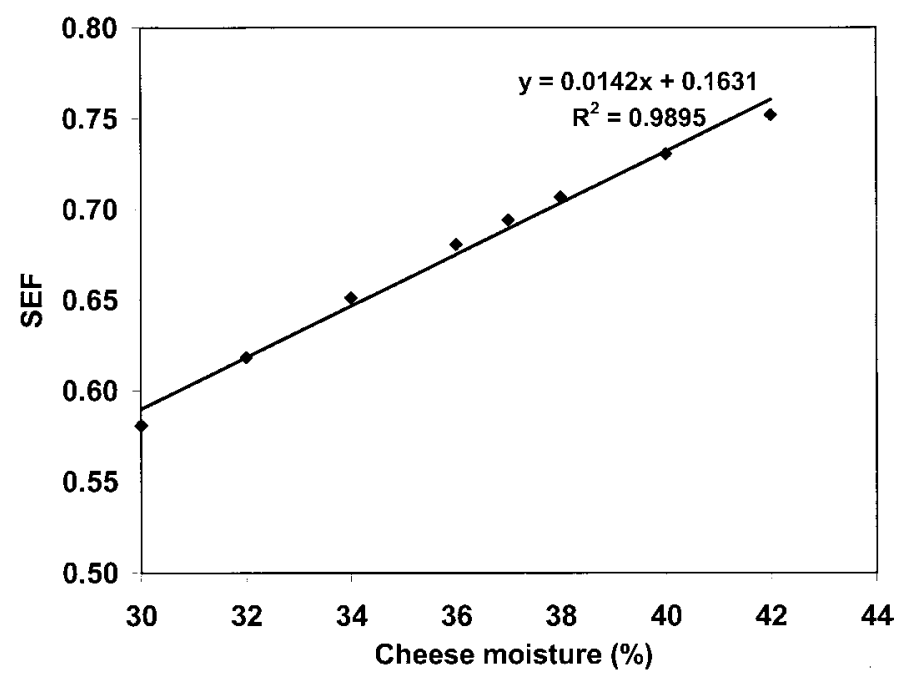

Figure 1. Solute exclusion factor (SEF) for use in the Barbano theoretical yield formula as a function of Cheddar cheese moisture content.

from the data in the present study for Cheddar cheese at $35.25 \%$ moisture is $0.670 \pm 0.11$.

The SEF for Cheddar cheese is expected to be different for Cheddar cheese with different moisture content. Using the data from the control cheeses in the present study, the predicted SEF to be used in the Barbano cheese yield formula was calculated for a range of moisture contents (from 30 to $42 \%$ for Cheddar cheese; Figure 1). As cheese moisture increases, an increasing proportion of the total cheese moisture is available to act as a solvent for nonfat, noncasein milk solids. The SEF for cheese moisture of $37 \%$ (target) was calculated as 0.6941. This SEF value was used for calculation of the Barbano theoretical yields (Table 4).

Cheese yield and efficiency. The actual, adjusted (to $37 \%$ moisture and $1.5 \%$ salt), and theoretical yields (both the Van Slyke and the Barbano) increased $(P<$ 0.01) significantly with increasing CF (Table 4). The adjusted yields are always higher than the actual yields in this study because actual moisture content of all cheeses was always lower than the target moisture content (i.e., 37\%). The composition adjustment also included adjustment to a desired salt content of $1.5 \%$, which was very close to the observed salt content of the cheeses (ranged from 1.46 to $1.51 \%$ ). St-Gelais et al. (1995) have shown that both the actual and the adjusted (to $37 \%$ moisture and $1.7 \%$ salt) Cheddar cheese yields increased significantly with increasing CF. Our results agree with those of St-Gelais et al. (1995). This suggests that milk enriched with MF retentate can greatly improve manufacturing efficiency by spreading fixed equipment, utility, and labor costs over more pounds of cheese produced per day, if the amount of raw milk purchased by a factory is increased, as reported previously for evaporation, reverse osmosis, and LCF UF (Aplin et al., 1992).

Cheese yield efficiency is used to compare the composition-adjusted yield with the theoretical (predicted) yields. In our study, no significant difference $(P>0.05)$ in cheese yield efficiency due to MF was detected using either the VanSlyke or the Barbano formula. Therefore, the use of $\mathrm{MF}$ in the $\mathrm{CF}$ range up to $1.82 \times$ will not result in any more cheese obtained from the same amount of

Table 4. Mean $(\mathrm{n}=4)$ actual, composition adjusted, theoretical (Van Slyke and Barbano) cheese yields, and cheese yield efficiencies.

\begin{tabular}{|c|c|c|c|c|c|c|}
\hline & \multicolumn{4}{|c|}{$\mathrm{CF}^{1}$} & \multirow[b]{2}{*}{ SEM } & \multirow[b]{2}{*}{$P$-value } \\
\hline & $1.0 \times$ & $1.26 \times$ & $1.51 \times$ & $1.82 \times$ & & \\
\hline \multicolumn{7}{|l|}{ Yield } \\
\hline Actual & 8.81 & 11.12 & 13.33 & 15.86 & 0.050 & $<0.01$ \\
\hline Composition adjusted ${ }^{3}$ & 9.06 & 11.57 & 13.89 & 16.68 & 0.038 & $<0.01$ \\
\hline Theoretical $^{4}$ & & & & & & \\
\hline Van Slyke & 9.13 & 11.59 & 13.93 & 16.83 & 0.022 & $<0.01$ \\
\hline Barbano $^{5}$ & 9.13 & 11.58 & 13.92 & 16.81 & 0.022 & $<0.01$ \\
\hline \multicolumn{7}{|l|}{ Cheese yield efficiency ${ }^{6}$} \\
\hline Van Slyke & 99.23 & 99.83 & 99.71 & 99.11 & 0.255 & NS \\
\hline Barbano & 99.28 & 99.93 & 99.80 & 99.23 & 0.251 & NS \\
\hline
\end{tabular}

${ }^{1} \mathrm{CF}=$ Concentration factor.

${ }^{2} \mathrm{SM}=$ Standardized milk.

${ }^{3}$ Adjusted to $37 \%$ moisture and $1.5 \%$ salt.

${ }^{4}$ Using $93 \%$ fat recovery in cheese, target moisture $37 \%$, and target salt of $1.5 \%$.

${ }^{5}$ Using solute exclusion factor (SEF) of 0.6941 and calcium phosphate retention factor of 1.092 .

${ }^{6}$ Cheese yield efficiency $=$ composition adjusted yield divided by theoretical yield. 
original unconcentrated milk. However, as noted in the discussion for the fat recovery, separation of whole milk into skim and cream and recombination may cause higher losses of fat in whey independent of MF.

\section{CONCLUSIONS}

Cheddar cheese moisture content decreased with increasing MF CF. Standardization of milk to a constant CN-to-fat ratio, as suggested by St-Gelais et al. (1995), did not eliminate the effect of MF on cheese moisture content. Further modifications of the cheese making procedure when using MF concentrates will be required to achieve moisture content comparable to cheese made from unconcentrated milk.

Fat recovery in the cheese was not influenced by MF. Fat recoveries in both control and MF Cheddar cheeses were lower than the theoretical fat recovery (93\%) and lower than the fat recovery observed in previous studies (Lau et al., 1990; Barbano et al., 1991; Barbano and Rasmussen, 1992) in our laboratory. St-Gelais et al. (1995) also reported fat recoveries for control and $\mathrm{MF}$ cheeses that were lower than $93 \%$. It appears that separation of cream prior to MF, followed by the recombination of skim or MF retentate with cream resulted in lower fat recovery in cheese and higher fat lost in whey. Further work is needed on this issue.

$\mathrm{CP}$, calcium, and total solids recovery from the SM increased with increased $\mathrm{CF}$, due to the removal of some of these solids in the MF permeate prior to cheese making. Calcium and calcium as a percentage of protein increased in the cheese while PDB did not change. Thus, it appears that there was a real increase in calcium retention in the cheese due to $\mathrm{MF} \mathrm{CF}$. CP recovery in the cheese in this study was lower for control Cheddar cheeses compared to previous yield studies (Lau et al., 1990; Barbano et al., 1991; Barbano and Rasmussen, 1992) and that of St-Gelais et al. (1995). This was primarily due to a higher starting NPN concentration in the milk in the current study.

As expected, the actual and composition adjusted cheese yields increased with increasing MF CF. However, no effect of MF CF on cheese yield efficiency was detected. Thus, over the range of CF used in this study, a cheese maker would obtain the same amount of cheese from the same amount of original milk.

\section{ACKNOWLEDGMENTS}

The authors thank Joanna Lynch, Maureen Chapman, Laura Landolf, Pat Wood, Bob Kaltaler, Nancy
Carey, and Paula Benitez for technical support and the Northeast Dairy Foods Research Center and Dairy Management, Inc. (Rosemont, IL), the America-Mideast (AMIDEAST) Educational and Training Services, Inc. (Washington, DC), and the Hochstrasser Endowment for financial support.

\section{REFERENCES}

Aplin, R. D., D. M. Barbano, and S. J. Hurst. 1992. Comparison of the economics of Cheddar cheese manufacture by conventional and milk fractionation/concentration technologies. Part 5 of a research effort on Cheddar cheese manufacturing. A. E. Res. 92.2, Cornell Univ., Ithaca, NY.

Association of Official Analytical Chemists. 2000. Official Methods of Analysis. 17th ed. AOAC, Gaithersburg, MD.

Barbano, D. M., R. R. Rasmussen, and J. M. Lynch. 1991. Influence of milk somatic cell count and milk age on cheese yield. J. Dairy. Sci. 74:369-388.

Barbano, D. M., and R. R. Rasmussen. 1992. Cheese yield performance of fermentation-produced chymosin and other milk coagulants. J. Dairy Sci. 75:1-12.

Barbano, D. M. 1996. Mozzarella cheese yield: factors to consider. Page 29-38 in Proc. Seminar on Maximizing Cheese Yield. Center for Dairy Research, Madison, WI.

Creamer, L. K., M. Iyer, and J. Lelievre. 1987. Effect of various levels of rennet addition on characteristics of Cheddar cheese made from ultrafiltered milk. N.Z. J. Dairy Sci. Technol. 22:205-214.

Garrett, N. L. T. 1987. Continuous production of Cheddar cheese according to the Sirocurd method. Eur. Food Dairy J. 53 (5):135-143.

Green, M. L., F. A. Glover, E. M. W. Scurlock, R. J. Marshall, and D. S. Hatfield. 1981. Effect of use of milk concentrated by ultrafiltration on the manufacture and ripening of Cheddar cheese. J. Dairy Res. 48:333-341.

Horton, B. S. 1997. Whatever happened to the ultrafiltration of milk? Aust. J. Dairy Technol. 52(1): 47-49.

Jost, R., R. Brandsma, and S. Rizvi. 1999. Protein composition of micellar casein obtained by cross-flow microfiltration of skimmed milk. Int. Dairy J. 9:389-390.

Lau, K. Y., D. M. Barbano, and R. R. Rasmussen. 1990. Influence of pasteurization on fat, and nitrogen recoveries, and Cheddar cheese yield. J. Dairy Sci. 73:561-570.

Lelievre, J., L. K. Creamer and K. L. Tate. 1990. Inhibition of calf vell and microbial rennet action by whey protein concentrate. Milchwissenschaft. 45:2:71-75.

Marshall, R. T., ed. 1992. Standard Methods for the Examination of Dairy Products. 16th ed. Am. Publ. Health Assoc., Inc., Washington, DC.

Metzger, L. E., D. M. Barbano, M. A. Rudan, and P. S. Kindstedt. 2000. Effect of preacidification on low fat Mozzarella cheese. I. Composition and yield. J. Dairy Sci. 83:648-658.

Rudan, M. A., D. M. Barbano, J. J. Yun, and P. S. Kindstedt. 1998. Effect of fat replacer (Salatrim ${ }^{\circledR}$ ) on chemical composition, proteolysis, functionality, appearance and yield of reduced fat Mozzarella cheese. J. Dairy Sci. 81: 2077-2088.

Rudan, M. A., D. M. Barbano, J. J. Yun, and P. S. Kindstedt. 1999. Effect of fat reduction on chemical composition, proteolysis, functionality and yield of Mozzarella cheese. J. Dairy Sci. 82:661-672.

SAS User's Guide: Statistics, Version 6 Edition. 1990. SAS Inst., Inc., Cary, NC.

St-Gelais D., M. Piette, and G. Belanger. 1995. Production of Cheddar cheese using milk enriched with microfiltered milk retentate. A preliminary study. Milchwissenschaft 50(11):614-618.

Swientek, R. J. 1984. Continuous cheese making process utilizes ultrafiltration technology. Food Proc. 45 (12):103-106. 